\title{
SLOVAK VIRTUAL MARKET IN THE LIGHT OF ANALYSIS OF POSSIBILITIES OF DETECTING ON-LINE REPUTATION FOR SELECTED SUBJECTS
}

The main aim of this article is to analyze the theoretical possibilities of detecting an On-Line reputation of selected subjects functioning on Slovak virtual market. The purpose of article is also to present selected method of measuring on-line reputation of selected subjects based on newest knowledge in the field of managerial sciences. For purposes of this article, subjects are represented by on-line presence of Slovak towns in a virtual market place. In particular, cultural and anthropological context, and the resulting specificities and peculiarities typical of the post-communist block of countries will be taken into account in relation to the chosen market. The target group is narrowed to 20 biggest Slovak towns as the best representation of subjects which officially presented themselves to internet users on the specific type of market.

Keywords: Reputation, On-Line reputation, SME, Market, Entrepreneurship, Competition, Image, Internet, Social Networks, Virtual Social Networks.

\section{Introduction}

The issue of the use of internet tools in marketing is in itself still very young. However, we may definitely conclude that any new techniques and media used within the portfolio of marketing tools can help distinguish an entity from the competition [1]. The competition is huge for both commercial and noncommercial entities. Times when the „only“ thing necessary for market prosperity was a quality product are long gone [2]. It is becoming increasingly difficult to reach the target audience. Overcapacity of advertising messages on the market is a problem the marketing managers worldwide must deal with on a daily basis [3]. Regardless of the resources and effort it is often the case that the advertising message disappears, or simply ceases to exist in the context of other more or less important information of various kinds. An appropriate solution in marketing practice is especially reduction of communication paths through the use of the internet and its tools. The internet offers us the possibility of a clear and precise message targeting of selected market, often to the individuals themselves. It also significantly reduces the communication path when the entities are allowed to communicate directly with their customers. Customers, in this case internet users, demand themselves the information, thereby significantly increasing the rate of adoption of communicated message. Thanks to its nature the internet allows for easy sharing and transfer of information and creates space for entities whose motives may not always be ethical [4]. The issue of reputation is therefore highly relevant issue in the context of virtual identity of entities using the internet to communicate. Undoubtedly, companies with a high reputation have at present a competitive advantage in terms of customer acquisition [5]. It has been shown that $80 \%$ of customers prefer the company with a high reputation rather than an average company or a company with a dubious reputation. In Slovakia, this area has been examined to some extent in relation to banking entities [6]. Such factors have been analyzed as value, quality of products or social activities of companies. Subsequently, it has been examined how these factors are perceived and evaluated by the consumers, customers, business partners, the public and so on.

\section{The issue of reputation in the times of the internet and modern technology}

New technologies, forms of communication, as well as the internet itself, are on the one hand positive aspects of this age but, on the other hand, they entail a risk. Dissemination of negative information, rumors or false information through these media is very quick and uncontrollable. Based on the above arguments a study has been carried out in Washington [7], which has examined the relationship of reputation management and current social media. A similar survey regarding online communication

\footnotetext{
* ${ }^{1}$ Peter Dorcak, ${ }^{2}$ Frantisek Pollak, ${ }^{2}$ Martin Mudrik, ${ }^{2}$ Ludovit Nastisin ${ }^{1}$ Goethe UNI, Bratislava, Slovakia

${ }^{2}$ Department of Marketing and International Trade, Faculty of Management, University of Presov, Slovakia

E-mail: peter@dorcak.com
} 
has been conducted at the University of Singapore [8] and it has provided a clear view of the relationship between these poles. In the context of scientific literature focusing on e-marketing, specifically on the field of online reputation, conceptual or rather empirical studies are available in limited quantities. The claim in question is referred to by the author [9] who states that despite the lack of analyses many authors believe that reputation is much more important in online than in offline context because factors determining trust in offline context are absent and are not yet known [10]. Reference [11] defines online social media as open interactive online applications which support the development of informal user networks. Users create and share various contents in these networks, such as personal experience, opinions, videos, music and photos. The most important online social media include online social networks, blogs, forums and other online communities. However, this division is somehow problematic because, in practice, the media overlap.

In our territory, we can currently see an enormous increase in the use of social media services. A good example is the largest social network in the world, Facebook, which is with its more than 500 million registered and more than $50 \%$ of daily active users successful also in Slovakia. 1.5 million registered people in Slovakia prove it. The age group which is most represented are the users aged between 18 and 24 years (32\%), followed by a group aged between 25 and 34 years (29\%) [12]. The importance of social media has been indicated in the works of foreign scientists and scientific teams published in the Journal of Marketing Research, under the auspices of the American Marketing Association - AMA. Their research has been in particular focused on the perception of the value of social networks by consumers [13], the analysis of marketing strategies and social media [14], the potential of social networks for the development of e-business [15], the impact of social networks on consumer decisions [16]. Virtual social networks are currently the focus of several authors. From all of these authors we may mention Robert Cross and Robert Thomas who in their writings explore the perception of the value of social networks by consumers [17]. American professor Wehr, for example, has been working on the analysis of marketing strategies of social media for three years.

\subsection{Reputation and the possibility of its measurement, various methodologies used in determining reputation}

Worldwide research in the area of reputation which has been conducted at the University of Oxford [18] shows that reputation is made up of two elements: customer opinion of the respective company and the real truth about the company and its commercial policy, procedures, management system and financial performance. Other research shows that reputation may be responsible for 8 to $15 \%$ of the value of company shares in business sector. Authors [19] concluded that a company has a good reputation if it always meets or exceeds the expectations of its customers and vice versa, a company has a bad reputation if it does not meet these expectations. Consequently, they proposed the following formula for reputation: Reputation = experience - expectations. At any moment, customers measure reputation by comparing current experience in contrast to their expectations [20]. This formula for the evaluation of reputation can be complemented by the trust evaluation model presented by [21] in 2005. They claim that Trust $=0.5^{*}$ Reputation $+0.5^{*}$ Cooperation.

Particularly important is the process of identification of the most important factors that determine the reputation of a company. Fombrun prepared a methodology to measure the perception of the company through the prism of its major shareholders. He introduced 20 factors that affect reputation based on 6 criteria [22]. These factors include, for example, emotional factors, products and services, vision and leadership or social responsibility of the company. Some of the most complex structures of reputation factors are specified by Turner. Not only he defines eight main reputation factors, but for each of them he also provides sources of information that affect them. In addition, these factors may be divided into rational and emotional [23]. It should be noted that the above factors may help to improve the company's reputation but, at the same time, they may also severely worsen it. Their initial identification is a very important point in building the reputation of management in the company. It's a long, time consuming process, and actual results are only achieved from a long-term perspective. That is why it is appropriate to use the research and experience of the company which analyse the impact of individual factors on the level of reputation.

In 2006, an interesting study was carried out by [24] entitled "Protection of reputation". The study included 950 managers and directors representing companies from 11 countries. The results were divided into four regions: World, North America, Europe and Asia. The most important factors that are able to destroy reputation identified by the executives include: financial fraud, unethical behaviour, illegal data collection, irresponsibility towards environment and violations of safety and health regulations.

\section{Analysis of reputation of selected entities on Slovak virtual market}

Managing a virtual reputation, or in other words, On-line Reputation Management (ORM) is neither new nor unknown term in Slovakia. ORM has been applied in many industries such as banking or insurance. The results of these surveys have provided a realistic and current view on the virtual presentation of organization as well as the image of their virtual identities. 
The level of positive on-line reputation is not only a source of information for the organizations themselves, but also an important factor influencing decision-making of consumers.

For the purpose of this analysis the online reputation of twenty largest Slovak towns as the best representatives of entities officially presenting themselves directly to target customers and internet users in the environment of specific virtual market was established by a selected methodology. The used methodology is called „sentiment analysis“ [25]. The presented methodology can be subsequently used for the purposes of the on-line reputation survey of the various entities, for example SME's, public institutions, or even individuals using the internet for personal branding. The sequence of the process of measuring reputation begins with defining the representatives of investigated segment, in this case, chosen specific Slovak towns. Consequently, virtual identity of these entities is investigated by means of Google search. When analyzing sentiment, the first 10 search results are taken into consideration. To ensure the objectivity of results, which may be distorted by the tendency of search engines to personalize the search based on the history of the internet activity,

Sentiment of results / position of results [25]

Table 1

\begin{tabular}{|l|c|c|c|c|c|c|c|c|c|c|}
\hline Sentiment/Position of the result & 1 & 2 & 3 & 4 & 5 & 6 & 7 & 8 & 9 & 10 \\
\hline $\begin{array}{l}\text { Positive sentiment } \\
+\end{array}$ & 20 & 19 & 18 & 17 & 16 & 15 & 14 & 13 & 12 & 11 \\
\hline $\begin{array}{l}\text { Own Website of the town } \\
\mathrm{X}\end{array}$ & 10 & 9 & 8 & 7 & 6 & 5 & 4 & 3 & 2 & 1 \\
\hline $\begin{array}{l}\text { Neutral sentiment } \\
\pm\end{array}$ & 2 & 2 & 2 & 2 & 2 & 2 & 2 & 2 & 2 & 2 \\
\hline \begin{tabular}{l} 
Negative sentiment \\
\hline
\end{tabular} & -20 & -19 & -18 & -17 & -16 & -15 & -14 & -13 & -12 & -11 \\
\hline
\end{tabular}

Overall rating of sentiments of twenty largest Slovak towns [own elaboration according to 25]

Table 2

\begin{tabular}{|l|c|c|c|c|c|c|c|c|c|c|c|}
\hline Town / Sentiment result position & 1 & 2 & 3 & 4 & 5 & 6 & 7 & 8 & 9 & 10 & Result \\
\hline Komarno & $\mathrm{x}$ & $\mathrm{x}$ & \pm & + & \pm & + & \pm & $\mathrm{x}$ & \pm & + & $\mathbf{7 3}$ \\
\hline Bardejov & $\mathrm{x}$ & \pm & + & + & \pm & $\mathrm{x}$ & \pm & + & \pm & $\mathrm{x}$ & $\mathbf{7 2}$ \\
\hline Nitra & $\mathrm{x}$ & \pm & \pm & + & + & + & \pm & \pm & \pm & \pm & $\mathbf{7 0}$ \\
\hline Michalovce & $\mathrm{x}$ & $\mathrm{x}$ & $\mathrm{x}$ & \pm & \pm & \pm & + & + & \pm & \pm & $\mathbf{6 4}$ \\
\hline Kosice & $\mathrm{x}$ & + & \pm & \pm & \pm & + & + & \pm & \pm & \pm & $\mathbf{6 0}$ \\
\hline Martin & $\mathrm{x}$ & \pm & \pm & \pm & + & + & \pm & \pm & \pm & \pm & $\mathbf{5 5}$ \\
\hline Trencin & $\mathrm{x}$ & \pm & \pm & \pm & + & \pm & + & \pm & \pm & \pm & $\mathbf{5 4}$ \\
\hline Poprad & $\mathrm{x}$ & \pm & + & \pm & \pm & \pm & \pm & \pm & + & \pm & $\mathbf{5 4}$ \\
\hline Prievidza & $\mathrm{x}$ & \pm & \pm & \pm & + & \pm & \pm & \pm & \pm & \pm & $\mathbf{4 2}$ \\
\hline Spisska Nova Ves & $\mathrm{x}$ & \pm & \pm & \pm & + & \pm & \pm & \pm & \pm & \pm & $\mathbf{4 2}$ \\
\hline Zvolen & $\mathrm{x}$ & \pm & \pm & \pm & \pm & + & \pm & \pm & \pm & \pm & $\mathbf{4 1}$ \\
\hline Bratislava & $\mathrm{x}$ & \pm & \pm & \pm & \pm & \pm & + & \pm & \pm & \pm & $\mathbf{4 0}$ \\
\hline Presov & $\mathrm{x}$ & \pm & \pm & \pm & \pm & \pm & + & \pm & \pm & \pm & $\mathbf{4 0}$ \\
\hline Levice & $\mathrm{x}$ & $\mathrm{x}$ & \pm & \pm & \pm & \pm & \pm & \pm & \pm & \pm & $\mathbf{3 5}$ \\
\hline Nove Zamky & $\mathrm{x}$ & \pm & \pm & \pm & $\mathrm{x}$ & \pm & \pm & \pm & \pm & \pm & $\mathbf{3 2}$ \\
\hline Humenne & $\mathrm{x}$ & \pm & \pm & \pm & $\mathrm{x}$ & \pm & \pm & \pm & \pm & \pm & $\mathbf{3 2}$ \\
\hline Zilina & $\mathrm{x}$ & \pm & \pm & \pm & \pm & \pm & \pm & \pm & \pm & \pm & $\mathbf{2 8}$ \\
\hline Banska Bystrica & $\mathrm{x}$ & \pm & \pm & \pm & \pm & \pm & \pm & \pm & \pm & \pm & $\mathbf{2 8}$ \\
\hline Trnava & $\mathrm{x}$ & \pm & \pm & \pm & \pm & \pm & \pm & \pm & \pm & \pm & $\mathbf{2 8}$ \\
\hline Povazska Bystrica & $\mathrm{x}$ & \pm & - & \pm & \pm & \pm & \pm & - & \pm & \pm & $-\mathbf{7}$ \\
\hline
\end{tabular}

Note: In determining the sentiment the numbers of positive reviews on social networks were not taken into account. Only the fact that the town owns a profile on any of the virtual social networks was taken into account. The nature of the town descriptions on the Wikipedia portal was also not taken into account. Only the fact that Wikipedia mentions the town was taken into account. In both cases, these results were assigned neutral sentiment. If the search engine found, besides an official town's web site, web pages of entities associated with such town on other places in a search, these results were assigned neutral sentiments. If the town's web site occurred in several places within the search, only the first occurrence was taken into account, where the following occurrences of town's web site were assigned neutral character. 
proxy anonymizers were used to ensure the greatest possible relevance of the findings. Only organic results were included in the survey. The search phrase was always a well-known and well established town name, regardless of the homepage. One of the main factors in the evaluation process is the sentiment of results. It may be broadly defined as a nature of found results after entering key words. The results may include positive, neutral, as well as negative feedback. These sentiments, as well as the position in which they appear, provide a picture of researched entity, and thus ultimately determine its online reputation. Sentiment of individual results in Top 10 is shown in the table below with a brief commentary. At the same time, each position is assigned a score based on the sentiment according to the following Table 1.

The table shows chronological sequence of awarding points to the analyzed entities. Positive response or sentiment results in the increase of the score. The higher the position of this sentiment in the search result, the more points are awarded. Similarly, but with the opposite effect, it works in identifying the negative sentiment. Points are deducted, the higher the position of the display, the bigger the deduction of points, and this significantly deteriorates the reputation. Next, individual sentiments are counted as a part of the overall evaluation and the resulting number indicates the strength of the sentiment of all ten search results for the town / entity. The resulting number of sentiments stands for the overall level (power) of the online reputation. The entities are then listed for comparison in ascending order based on their overall level of online reputation in a virtual environment of the Slovak internet. Table 2 of the overall evaluation of sentiments of twenty largest Slovak towns (and, therefore, the overall level of their online reputation) looks as follows.

\section{Evaluation of the analysis and discussion}

The above analysis of virtual identity of researched entities twenty biggest Slovak towns - clearly shows that the first search results are dominated by the towns'own websites or the websites managed by the towns. Search results of neutral sentiment formed the largest group of sentiments. Only one entity showed negative sentiment, and even two negative sentiments, on the third and the eighth place in the search results (town of Povazska Bystrica had a negative evaluation due to the transport infrastructure of the city). In respect to virtual reputation among internet users, entities in the leading positions have an advantage as their complex virtual identity is perceived more positively.

In case the user is searching for information on a particular town and comes across some negative references, it may ultimately affect his/her overall perception of the destination. Especially if the user is a tourist who personally never visited the town or the area and forms his/her view strictly on the basis of the information from the virtual environment. The same applies to potential investors. Towns should therefore make sure that the necessary information available to potential visitors is as clear as possible. It is in their interest to eliminate negative publicity (and enhance positive publicity), at least in the first ten search results. This can be achieved by active internet communication policy, i.e. spreading positive information on renowned internet portals, such as electronic forms of major Slovak newspapers or virtual social networks. The best way to eliminate negative or neutral publicity in the first ten search results is literally a displacement of such publicity by active work (for example, by means of a coherent marketing communication policy) on the internet. As mentioned above, the presented methodology is one of many methodologies used for the determination and measurement of online reputation. However, the complexity of this methodology, its transparency and the fact that it is less time consuming, makes it ideal for identifying online reputation of different entities, such as SMEs, public institutions and even individuals using the internet for their personal branding.

\section{Conclusion}

In today's post-industrial society, power elites come to the fore through the use of new technologies. There is a general willingness when applying marketing tools to build quality and strong brand and its presentation for wider area. It does not matter whether it is a city or town, product, service, or organization. This study pointed out the importance of reputation in the online world that can harm the brand or damage its image within a millisecond when searching information on the internet. For the purpose of this paper a ranking of levels of online reputation for biggest Slovak cities was processed and it showed great differences. The result of the perception of reputation, on the basis of this paper, may be correct and targeted communication, which is part of the marketing mix. Positive reputation, especially in the online environment of immediate decisions is often a critical factor in the realization of customer products purchase, city or town visit, or ordering service. In addition to a long built positive image it is therefore important to regularly verify the level of reputation and eliminate negative news.

\section{Acknowledgement}

This article is one of the partial outputs of the current research grant VEGA No. 1/0145/14 entitled "Online Reputation Management (ORM) as a Tool to Increase Competitiveness of Slovak SMEs and its Utilization in Conditions of Central European Virtual Market”. 


\section{References}

[1] ZGODAVOVA, K. BOBER, P.: An Innovative Approach to the Integrated Management System Development: SIMPRO-IMS Web Based Environment. Quality Innovation Prosperity, vol. 16, No. 2, 59-70, 2012.

[2] BACIK, R.: Increase of the Competitiveness of Small and Medium Businesses in Presov with the Assistance of Specific Marketing Instrumentation. Management 2008, 181-190. ISBN 978-80-8068-849-3.

[3] SOVIAR, J.: Simplification of Marketing Scheme for Business Start-Ups. Communications - Scientific Letters of the University of Zilina, vol. 13, No. 4, 2011, 55-57. ISSN 1335-4205.

[4] SOVIAR, J., VODAK, J.: Value Network as Part of New Trends in Communication. Communications - Scientific Letters of the University of Zilina, vol. 14, No. 2, 2012. ISSN 1335-4205.

[5] HORVAT, M., MICHALKOVA. A.: Monitoring Customer Satisfaction in Service Industry: A Cluster Analysis Approach. Quality Innovation Prosperity, vol. 16, No. 1, 49-54, 2012.

[6] RAJZAK, P. et al.: System for Evaluation of Online Reputation of Banks (in Slovak). Faculty of Electrical Engineering and Informatics of the Technical University of Kosice, 652-657, 2010. ISBN 978-80-553-0460-1.

[7] MADDEN, M., SMITH, A.: Reputation Management and Social Media. [online]. [cit. 2013-03-03]. Available on the internet: <http://www.pewinternet.org/Reports/2010/ Reputation-Management/Summary-of-Findings.aspx>.

[8] ZHIGI, S. et al.: A Survey of Trust and Reputation Management Systems in Wireless Communications. University Singapore, 17551772, 2010. ISSN 0018-9219.

[9] ARGRYIOU, E., KITCHEN, P. J., MELEWAR, T. C.: The Relationship between Corporate Websites and Brand Equity: A Conceptual Framework and Research Agenda. Intern. J. of Market Research, vol. 48, No. 5, 559-575, 2006.

[10] LAJCIN, D., FRANKOVSKY, M., STEFKO, R.: Possibilities of Predicting the Behavior of Managers When Coping with Demanding Situations in Managerial Work. Ekonomicky casopis, vol. 60, No. 8, 835-853, 2012. ISSN 0013-3035.

[11] KRALICEK, J.: The Position of Consumer in Relationship Containing and International Element. Masarykova Univerzita, 2011, [online]. [cit. 2013-03-05]. Available on the internet: 〈http://is.muni.cz/th/170265/?lang=en>.

[12] SOCIALBAKERS.COM. Slovakia Facebook Statistics. [online]. [cit. 2013-03-04]. Available on the internet: <http://www. socialbakers.com/facebook-statistics/slovakia>.

[13] STEPHEN, A.T., TOUBIA, O.: Deriving Value from Social Commerce Networks, J. of Marketing Research, 2010, 215-228, ISSN 0022-2437.

[14] WEHR, L.: An Eye Tracking Analysis on Social Networking Sites. [online]. [cit. 2013-03-09]. Available on the internet: <http://www. ergophile.com/wp-content/uploads/2009/08/oneupweb_eye_tracking_study_2009.pdf>.

[15] ZEISSER, M.: Unlocking the Exclusive Potential of Social Networks. [online]. [cit. 2013-02-25]. Available on the internet: 〈http:// www.mckinseyquarterly.com/ Unlocking_the_elusive_potential_of_social_networks_2623>.

[16] BULMER, D., DIMAURO, V.: The New Symbiosis of Professional Networks: Social Media's Impact on Business and Decision-Making. Palo Alto : Society for New Communications Research, 2010, 32 pp. ISBN 978-0982700402.

[17] CROSS, R. L., THOMAS, J.: Driving Results through Social Networks: How Top Organizations Leverage Networks for Performance and Growth. Hoboken : John Wiley \& Sons, 2009, p. 240, ISBN 978-0470481189.

[18] SCHULZ, H. B., WERNER, A.: Reputation Management, Human Resources Management. [online]. [cit. 2013-02-19]. Available on the internet: <http://www.oxford.co.za/download_files/cws/Reputation.pdf>.

[19] LUISOM, J. P., RAYNER, J., GAULTIER-GAILlARD, S.: Managing Risks in Reputation - From Theory to Practice, Reputation Capital. Springer-Verlag : Berlin : Heidelberg, 2009

[20] DELINA, R.: Trust Building Electronic Services as Crucial Self-Regulation Feature of Digital Business Ecosystems. IDIMT 2011: Schriftenreihe Informatik, vol. 36, 315-327, 2011.

[21] LAVARAC, N., LJUBIC, P., JermOL, M., BOLHALTER, S.: A Decision Support Approach to Trust Modeling in Networked Organizations, Collaborative Networks and Breeding Environments. Norwell : Camarinha-Matos L. M. (ed.), the Kluwer Academic Publishers - Springer, 2005, p. 170.

[22] FOMBRUN, C. J., VEIL VAN, C. B. M.: How Successful Companies Build Winning Reputations. New Jersey : FT Press, 2003

[23] TURNER, M.: Reputation, Risks and Governance. Effective Risk and Business Management Topic Paper, No. 6, The Housing Corporation, 2004, p. 3.

[24] SHANDWICK, W., KRC, R.: Safeguarding Reputation. [online]. [cit. 2013-02-27]. Available on the internet: <http://www. reputationrX.com/>.

[25] ROHAL, R., SASKO, J.: Sentiment Analysis of Results of Slovak Companies (in Slovak). [online]. cit. 2013-03-10]. Available on the internet: 〈http://www.reputation.sk/ whitepapers/Analyza_sentimentu_reputation_sk.pdf〉. 